\title{
ANALISIS PEMANFAATAN UANG LOGAM BERBASIS TEKNOLOGI FINANSIAL
}

\author{
Rizkia Ninda Aulia \\ Ekonomi Pembangunan, Fakultas Ekonomi dan Bisnis \\ Universitas Ahmad Dahlan \\ e-mail : rizkianindaaulia@gmail.com \\ Diki Bintoro \\ Ekonomi Pembangunan, Fakultas Ekonomi dan Bisnis \\ Universitas Ahmad Dahlan \\ Herri Kurnia \\ Teknik Informatika, Fakultas Teknik \\ Universitas Ahmad Dahlan
}

\begin{abstract}
The inflow and outflow rates of coins that were not commensurate made the money supply, especially coins in society, too large. Starting from this problem, the researcher aims to help the community manage coins with better utilization by designing financial technology, namely a mobile-based application made for KoKo coins (Coin Box). This research is a descriptive qualitative research with the results of an online banking application. The method used in data collection is the distribution of questionnaires with time dimensions that are cross section because data collection was carried out at Campus 1 UAD with a sample of 100 respondents in one period. Based on the results of observations, there were $52.7 \%$ of UAD campus 1 residents who had coins with a nominal value of Rp. 500 and the rest were nominal below that. The percentage of coin ownership has an impact on responses to the use of coins with the application and features in the application, which is $65.5 \%$ of the total respondents. This application can be used by first registering as a KoKo customer by entering personal data at the registration stage which will be verified via email of the prospective customer. After successful registration and login, customers can save their coins by allocating savings, bank transfers, donations and even investing in time deposits. The expected influence in society is that this application can assist the community in managing the coins they have and a balanced level of inflow and outflow in the circulation of money.
\end{abstract}

\begin{abstract}
ABSTRAK
Tingkat inflow dan outflow uang logam yang tidak sepadan membuat jumlah uang beredar khususnya uang logam di masyarakat terlalu besar. Berawal dari permasalahan tersebut, peneliti bertujuan untuk membantu masyarakat dalam mengelola uang logam dengan pemanfaatan yang lebih baik dengan merancang teknologi finansial yaitu aplikasi berbasis mobile yang dibuat untuk uang logam KoKo (Kotak Koin). Penelitian ini berbentukk kualitatif deskriptif dengan hasil produk sebuah aplikasi perbankan online. Metode yang digunakan dalam pengumpulan data adalah penyebaran kuisioner dengan dimensi waktu yang bersifat cross section karena pengambilan data dilakukan di Kampus 1 UAD dengan sampel sebanyak 100 responden dalam satu periode. Berdasarkan hasil dari observasi, terdapat $52,7 \%$ warga kampus 1 UAD yang memiliki uang logam dengan nominal Rp 500 dan sisanya
\end{abstract}




\section{Buletin Ekonomi}

adalah nominal dibawah itu. Persentase kepemilikan uang logam tersebut berdampak pada tanggapan untuk adanya pemanfaatan uang logam dengan aplikasi dan fitur-fitur yang ada dalam aplikasi yaitu sebesar 65,5\% dari keseluruhan responden. Aplikasi ini dapat digunakan dengan mendaftar terlebih dahulu sebagai nasabah KoKo dengan memasukkan data diri pada tahapan registrasi yang akan terverifikasi melalui email calon nasabah. Setelah berhasil dalam registrasi dan login, nasabah dapat menabungkan uang logam yang dimilkinya dengan alokasi menabung, transfer antar bank, donasi bahkan investasi dalam bentuk deposito berjangka. Pengaruh yang diharapkan di masyarakat adalah aplikasi ini dapat membantu masyarakat dalam mengelola uang logam yang dimiliki dan tingkat inflow serta outflow yang seimbang dalam peredaran uang.

Kata Kunci : Uang Logam, Teknologi Finansial, Nasabah, Tabungan

\section{PENDAHULUAN}

Uang memiliki fungsi sebagai media pertukaran, sebagai penyimpan nilai dan sebagai satuan hitung (Mankiw, 2006). Fungsi media pertukaran, uang berperan dalam proses transaksi yang menjadi roda peredaran uang di suatu negara. Uang terdiri dari dua jenis, yaitu uang kartal dan uang giral. Uang giral terdiri dari uang logam dan uang kertas, dimana nilai pemanfaatan uang kertas dan uang logam mendapatkan perhatian yang berbeda di masyarakat. Hal tersebut disebabkan dari kelemahan uang logam yang berat dan kurang praktis. Hal ini didukung dengan dua laporan dari dua instansi berbeda mengenai produksi dan peredaran uang logam ini, yaitu Perum Peruri yang menyatakan bahwa sejak tahun 20122016 terdapat kenaikan produksi uang logam sebesar $40 \%$ pertahunnya. Di sisi lain, Bank Indonesia (2016) menyatakan bahwa produksi uang logam sebesar Rp 6 Triliun, namun hanya kembali sebesar Rp 900 Miliar setelah proses peredaran atau sebesar $16 \%$ saja. Hal tersebut menyebabkan tingkat inflow dan outflow uang logam tidak sepadan dan jumlah uang logam yang beredar dimasyarakat cukup besar. Uang logam yang belum kembali ke Bank Indonesia sebesar Rp 5,1 Triliun dan masih dipertanyakan keberadaanya. Tidak seimbangnya tingkat inflow dan outflow uang logam kemungkinan karena nominal pembayaran dalam keseharian sudah menggunakan nominal yang lebih besar dari Rp100, Rp200, dan Rp500, contoh kecil yang dapat diambil seperti membayar parkir yang sudah banyak menerapkan retribusi mulai dari Rp2000. Padahal, meskipun dengan nominal kecil, uang logam tetaplah memiliki fungsi yang sama dengan uang kertas yang memiliki nominal yang lebih besar.

Gubernur Bank Indonesia Agus D.W. Martowardjojo mencanangkan GNNT (Gerakan Nasional Non Tunai) yang bertujuan untuk meningkatkan kesadaran masyarakat, pelaku bisnis dan juga lembaga-lembaga pemerintah untuk menggunakan sarana pembayaran non tunai dalam melakukan transaksi keuangan, yang tentunya mudah aman dan efisien (Bank Indonesia, 2014). Agus D.W. Martiwardjojo (2014) yakin bahwa dengan kerjasama Bank Indonesia dengan pemerintah pusat dan daerah, kedepannya akan semakin banyak masayarakat yang beralih dari penggunaan instrumen tunai ke instrumen non tunai dalam aktivitas ekonominya, sehingga masyarakat non tunai dapat diwujudkan. Gerakan ini mendukung adanya peran teknologi finansial dalam kegiatan ekonomi. Adanya gerakan tersebut bersangkutan pula dengan adanya peredaran uang logam tunai yang masih beredar, lalu bagaimana cara agar uang logam berpotensi untuk mendukung Gerakan Nasional Non Tunai? Untuk itu, penting untuk mengkaji keberadaan uang logam dan potensi pemanfaatan uang logam di masyarakat.

Berdasarkan permasalahan yang telah dipaparkan, terdapat beberapa faktor penyebab peredaran uang logam yang belum efektif. Beberapa faktor tersebut seperti : 


\section{Buletin Ekonomi}

A. Bagaimana kepemilikan uang logam di masyarakat

B. Bagaimana pemanfaatan uang logam di masyarakat

C. Bagaimana strategi untuk pemanfaatan uang logam

D. Bagaimana penerapan pemanfaatan uang logam dengan teknologi finansial dalam rangka Gerakan Nasional Non Tunai

Berdasarkan permasalahan dari penelitian ini, dapat dirumuskan tujuan dari penelitian ini sebagai berikut :

A. Mengidentifikasi kepemilikan uang logam pada masyarakat

B. Mengidentifikasi pemanfaatan uang logam pada masyarakat

C. Merancang strategi untuk pemanfaatan uang logam yang dimiliki masyarakat

D. Menyukseskan Gerakan Nasional Non Tunai yang dicanangkan Bank Indonesia

Manfaat yang diharapkan dari aplikasi yang dibuat berdasarkan permasalahan yang ada sebagai berikut :

A. Meningkatkan pemanfaatan uang logam yang dimiliki masyarakat

B. Membantu masyarakat dalam pengelolaan dan pengalokasian uang logam yang dimiliki

C. Meningkatkan nilai uang logam dari pandangan umum masyarakat

D. Meningkatkan inflow uang logam yang beredar

Menyukseskan Gerakan Nasional Non Tunai dengan pemanfaatan uang logam berbasis aplikasi mobile.

\section{METODE}

Pengumpulan Data

Sumber data yang diobservasi berasal dari data primer, dengan alat analisis statistik distributif dan jenis data kuantitatif deskriptif. Dimensi waktu pelaksanaan observasi adalah cross section yang diambil dari 100 responden di Kampus 1 UAD yangterdiri dari mahasiswa, dosen dan karyawan. Proses pengambilan data adalah dengan pengisian kuisioner oleh responden secara online menggunakan Google Form.

\section{ANALISIS DAN PEMBAHASAN}

Berdasarkan hasil olah data diperoleh hasil mengenai kepemilikan, jumlah nominal, pemanfaatan dan penggunaan uang logam. Berikut penjelasan dari kepemilikan uang logam.

Tabel 1. Kepemilikan uang logam

\begin{tabular}{|c|c|c|}
\hline & $\mathrm{f}$ & $\%$ \\
\hline Memiliki & 99 & 99 \\
\hline Tidak memiliki & 1 & 1 \\
\hline Total & 100 & 100 \\
\hline
\end{tabular}

$\mathrm{f}=$ Frekuensi, $\%=$ persentase

Berdasarkan data yang dijelaskan pada Tabel.1, ditemukan bahwa 99\% responden memiliki uang logam. Kepemilikan uang logam oleh hampir seluruh responden ini berhubungan dengan laporan tahunan Bank Indonesia yang menerangkan bahwa dari Rp 6 Triliun uang logam yang diproduksi selama 10 tahun terakhir, hanya $16 \%$ saja atau Rp900 Miliar yang kembali ke Bank Indonesia (Bank Indonesia, 2016) dimana hal tersebut cukup menjelaskan bahwa Rp 5,1 Triliun uang logam masih beredar. 


\section{Buletin Ekonomi}

Nominal uang koin yang

paling banyak dimiliki

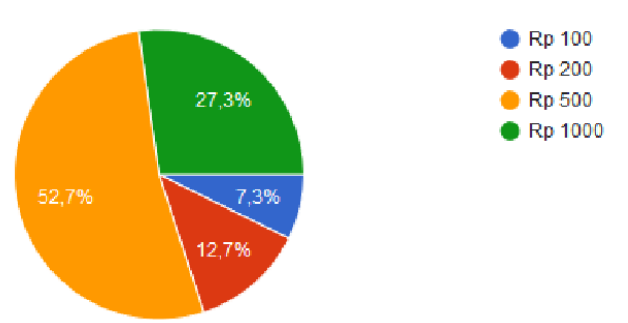

Gambar 1. Kepemilikan Uang Logam

Dari $99 \%$ yang menyatakan memiliki uang logam, sebesar 52,7\% didominasi uang logam dengan nominal Rp500. Disusul nominal Rp1000 dengan 27,3\%, Rp200 sebesar $12,7 \%$ dan Rp100 sebesar 7,3\%.

\section{Tanggapan mengenai maksimalisasi} pemanfaatan uang koin

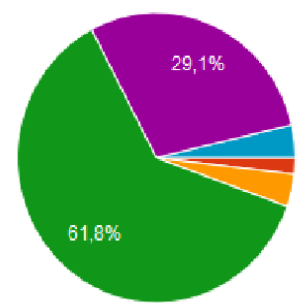

$$
\begin{aligned}
& \text { Sangat Tidak Setuju } \\
& \text { Tidak Setuju } \\
& \text { Kurang Setuju } \\
& \text { Setuju } \\
& \text { Sangat Setuju } \\
& \text { Netral }
\end{aligned}
$$

Gambar 2. Tanggapan Mengenai Maksimalisasi Pemanfaatan Uang Logam

Kepemilikan uang logam menjadi faktor adanya tanggapan baik atas maksimalisasi uang koin yang dialokasikan untuk kegiatan perbankan seperti menabung dan transfer, sosial seperti donasi, dan juga investasi.

Tanggapan mengenai penggunaan aplikasi Koko

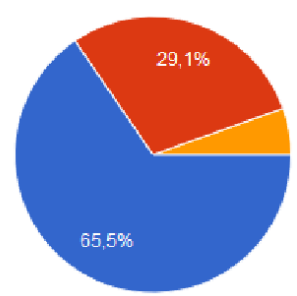

- Akan menggunakannya

Mungkin akan menggunakanny

Tidak akan menggunakannya

Gambar 3. Tanggapan Mengenai Penggunaan Aplikasi KoKo

Berikut adalah persentase tanggapan dari responden mengenai aplikasi Kotak Koin yang akan digunakan sebagai media untuk pengalokasian kepemilikan uang logam. Ditemukan bahwa sebesar 65,5\% responden akan menggunakan aplikasi Kotak Koin untuk memaksimalkan pemanfaatan uang logam yang dimiliki. 


\section{Buletin Ekonomi}

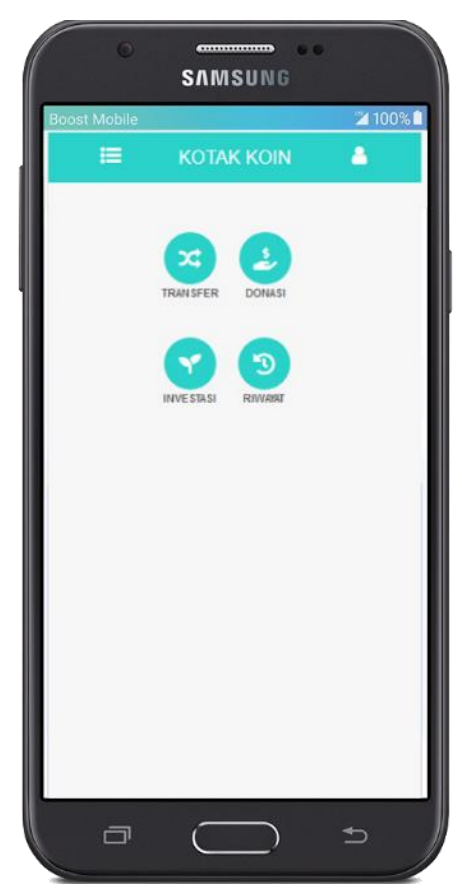

Gambar 4. Tampilan aplikasi KoKo pra monev

\section{KESIMPULAN DAN SARAN}

Kesimpulan yang didapatkan dari penelitian ini adalah dengan aplikasi ini dapat membantu warga Kampus 1 UAD secara khusus dan masyarakat Indonesia secara luas dalam mengelola uang logam yang dimilikinya untuk dialokasikan kepada hal yang lebih bermanfaat seperti tabungan yang dapat ditransfer antar bank, kegiatan sosial yaitu donasi dan kegiatan yang mendukung perekonomian yaitu investasi meskipun hanya dengan uang logam. Teknologi finansial KoKo dapat membantu Indonesia untuk meningkatkan inflow uang logam dan meningkatkan pemanfaatan uang logam secara umum.

Kesimpulan yang didapatkan adalah hampir seluruh responden memiliki uang logam yang didominasi dengan nominal Rp500 dan menyetujui adanya maksimalisasi pemanfaatan uang logam dengan aplikasi KoKo yang memiliki fitur transfer, donasi dan investasi untuk nasabah. Strategi pemanfaatan uang logam dengan aplikasi ini diharapkan dapat menyukseskan Gerakan Nasional Non Tunai yang dicanangkan oleh Bank Indonesia dengan meningkatkan inflow uang logam yang diinput dari KoKo dari nasabah.

\section{REKOMENDASI}

Salah satu gagasan yang tercetus dari peneliti sebagai solusi dari permasalahan diatas adalah aplikasi KoKo (Kotak Koin) yang dirancang untuk uang logam yang memiliki fungsi lainlain demi kemudahan pengguna aplikasi. Aplikasi KoKo dirancang sebagai teknologi finansial yang dimaksudkan untuk mempermudah layanan keuangan bagi konsumen. Bagi KoKo, tak hanya sebagai kemudahan untuk mengelola uang logam, tetapi dapat pula dialokasikan untuk hal-hal seperti donasi dan investasi. Istilah financial technology adalah penggunaan teknologi dalam sistem keuangan yang menghasilkan produk, layanan, teknologi, dan/atau model bisnis baru serta dapat berdampak pada stabilitas moneter, stabilitas sistem keuangan, dan/atau efisiensi, kelancaran, keamanan, dan keandalan sistem pembayaran (Bank Indonesia, 2017). Strategi pemanfaatan uang logam dengan teknologi finansial berupa KoKo ini diharapkan dapat menjembatani suksesnya Gerakan Nasional Non Tunai yang dicanangkan oleh Bank Indonesia. 


\section{Buletin Ekonomi}

\section{DAFTAR PUSTAKA}

Anggraeni, Ni Ketut Ayu. (2015) 'Peran bank Indonesia dalam pelaksanaan gerakan nasional non tunai (GNNT).

Bank Indonesia 2017. Teknologi Finansial. Diakses pada 17 Juli 2019. Tersedia di https://www.bi.go.id/id/sistem-pembayaran/fintech/Contents/default.aspx

Bank Indonesia, 2014. Bank Indonesia Mencanangkan Gerakan Nasional Non Tunai. Tersedia di https://www.bi.go.id/id/ruang-media/siaran-pers/Pages/sp_165814.aspx

Bank Indonesia, 2018. Statistik Sistem Pembayaran. Available at : https://www.bi.go.id/id/statistik/sistem-pembayaran/indikator-pengedaranuang/Contents/Default.aspx

Bank Indonesia. 2016. Bank Indonesia Ajak Masyarakat untuk Peduli Uang Koin. Diakses pada 14 Juni 2019. Tersedia di https://www.bi.go.id/id/ruang-media/infoterbaru/Pages/Bank-Indonesia-Ajak-Masyarakat-untuk-Peduli-Uang-Koin.aspx

Kompas. 2018. BI: Sepanjang 2017 Uang Kartal Beredar Capai Rp 694 Triliun Available at : https://ekonomi.kompas.com/read/2018/01/07/090000326/bi--sepanjang-2017-uangkartal-beredar-capai-rp-694-triliun. [Accessed August 24, 2018]

Mankiw, N. G. 2006. Pengantar Ekonomi Makro. $3^{\text {rd }}$ edn. Jakarta: Salemba Empat

Oktavia, Putu. (2007) 'Hubungan antara inflasi dan jumlah uang beredar’

Perusahaan Umum Percetakan Uang Republik Indonesia (Peruri). 2016. Laporan Tahunan. Diakses pada 14 Juni 2019

Sahar, F. H. and Setiartiti, L. (2016) 'Faktor-Faktor Yang Mempengaruhi Masyarakat Tidak Memakai Uang Logam Sebagai Alat Transaksi (Studi Kasus Di Kabupaten Pulau Morotai)', Jurnal Ekonomi \& Studi Pembangunan, 17(2), pp. 127-142. doi: 10.18196/jesp.17.2.3923. 